\title{
Atmosferiese stikstofopname deur sojaboonkultivars in kombinasie met Bradyrhizobium japonicum-rasse
}

\author{
A.D.P. Botha* en D.C. Pretorius \\ Instituut vir Grond, Klimaat en Water, Privaat sak X79, Pretoria, 0001 \\ R.L.J. Coetzer \\ Agrimetric Instituut, Privaat sak X640, Pretoria, (0001
}

Onwang 25 Maart 1996; aan'aar 22 Julie 1996

\section{UITTREKSEL}

\begin{abstract}
'n Sojaboon (Glycine max (L.) Merrill)-potproef is angeplant met drie kullivars (Forrest, Prima en A5409) wat tydens planting sonder (0) en met twee Bradyrhizobium japonicum-rasse (WBI en WB74) geinokuleer is. Die doel is on die effek van kultivarrhizobium-kombinasies op biomassa en $N$ afkomstig van die atmosfeer (Nava) le ondersoek en die almosferiese $N$-opname soos bepaal met die isotooptegniek, met die resultate van die konvensionele metode te vergelyk. Die grond is vooraf met ${ }^{\text {is }} N$ verryk. Die plante is na rypwording ge-oes en die droë massa van die plantkomponente bepaal. Plantdele is ontleed vir totale $N$ en atoom \% ${ }^{5} N$. Die Nava Iussen kultivar-rhizobiumras-kombinasies het verskil. Van die kontroleplante het Prima-0 die hoogste saadopbrengs, wat die hoogste konsentrasie en massa N bevat, gelewer: In kombinasie met die rasse WBI en WB74 het Forrest die hoogste saadopbrengs geproduseer, die meeste $N$ en atmosferiese $N$ opgeneem met gevolglik die grootste verdumning van die atoom \% ${ }^{\text {in }} \mathrm{N}$ in die saad. Vir die kultivars Prima en A5409, was die saadproduksie en die \% Nava acusienlik laer, en die totale $N$-konsentrasie en proteïeninhoud in die saad beduidend hö̈r as vir Forrest. Die kultivar-rhizobiumras-kombinasies se effektiwiteit ten opsigte van atmosferiese en totale $N$ opname in die saad was soos volg: Forrest-WBI > Forrest-WB74 > Prima-WB74 > A5409-WB74 > A5409-WBI > Prima-WBI. Die kombinasies met die grootste Nava het die atoom \% ${ }^{\prime \prime} \mathrm{N}$ in die saad die meeste verlaug. In die saad kan die \% Nava van die atoom \% ${ }^{15} \mathrm{~N}$ afgelei word. Ideale kondisies om die konvensionele metode toe te pas, heers nie onder veldtoestande nie en daarom word die isotooptegniek verkies. Sonder nodulering is baie minder saad met 'n laer $N$ en proteieninhoud geproduseer en daarom behoort opvolgnavorsing op inokulasietegnieke ter versekering van doeltreffende nodulasie te fokus.
\end{abstract}

\section{Abstract \\ Atmospheric nitrogen uptake by soyabean cultivars in combination with Bradyrhizobium japonicum strains A pot experiment was conducted, using three soyabean (Glycine max (L.) Merrill) cultivars (Forrest. Prima and A.5409) inoculated at planting, with no $(0)$ and two Bradyrhizobium japonicum strains (WBI and WB74). The objectives were to investigate the effect of cultivar-rhizobial strain combinations on biomass and $N$ derived from the almosphere (Ndfa) and to compare the atmospheric $N$}

- Outeur aan wie korrespondensie gerig kan word.

Huidige adres: l'osbus \$\$284, Linden, $210 \$$. 
uptake determined by the isotope techique, with the conventional method. The soil was enriched with ${ }^{15} \mathrm{~N}$ prior to the experiment. Plants were havested when ripe. The dry mass of the plant components were determined and the material analysed for total $N$ and atom \% ${ }^{15} \mathrm{~N}$. The Ndfa differed for the various cultivar-rhizobial strain combinations. For the control plants, Prima-O produced the biggest seed yield, with the highest $N$ concentration and mass of $N$. In combination with the rhizobial strains WBI and WB74, Forrest produced the highest yield, utilized the most $N$, and contained the highest \% Ndfa. The " ${ }^{5} \mathrm{~N}$ in the seed of Forrest was therefore the most diluted. For the Prima and A5409 culhivars the seed production and \% Ndfa were considerably lower; and the total N concentration and protein content of the seed significanly higher as for Forrest. The effectiveness of the cultivar-rhizobial strain combinations on almospheric $N$ and lotal $N$ at) take was: Forrest-WBI > Forrest-WB74 > Prima-WB74 > A5409-WB74 > A5409-WBI > Prima-WBl. The combinations with the highest Naffa diluted the ${ }^{15} \mathrm{~N}$ in the seed to the largest extent. In the seed the \% Naffa can be derived from the atom $\%{ }^{15} \mathrm{~N}$. Ideal conditions needed to apply the conventional method do not occur in field situations and therefore the isotope technique is preferred. Without nodulation much less seed with a low $N$ and protein content is produced. Follow-on research should therefore focus on inoculation techniques to ensure effective nodulation.

Keywords: Atmospheric N, ${ }^{15} \mathrm{~N}$ labelled soil N, N uplake, rhizobial strains, soyabean cullivars.

\section{INLEIDING}

Sojabone is die wêreld se belangrikste oliesaad en die gemiddelde opbrengs word op 1,9 ton ha'-1 beraam. 'Dic gemiddelde proteien- en olic-inhoud van sojaboonsaad is $40 \%$ en $21 \%$ respekticwelik. ${ }^{2}$ In dic VSA het die nasionalc opbrengs geleidelik van 1,6 ton ha. in 1960 tot 2,2 ton ha. in 1982 gestyg. ${ }^{3}$ SuidAfrika se gemiddelde sojaboonopbrengs in 1990-95 was 1,24 ton hal en die gemiddelde proteieninhoud vir 1993/94 slegs $34,5 \% .^{4}$ Opbrengste tot so hoog as 8,5 ton hat onder eksperimentele toestande toon dat die genetiese potensiaal ver bo die huidige produksievlakke lê. ${ }^{5.6} \mathrm{Om}$ in 'n vrye mark mec te ding en in Suid-Afrika se toenemende bekostigbare proteienbehoeltes te voorsien, behoort daar meer op dic lae ophrengs en proteieninhoud van sojaboongraan gefokus te word. Met beperkte nuwe landerye en die klem op volhoubare boerderystelsels, sal tocname in sojaboonproduksie in dic tockoms van die verhoogde, hočkwaliteitproduksie per eenheid oppervlakte afhang. Verbeterde $N$-benutting is ' $n$ bepalende faktor om sowel sojaboonproduksic as die proteïeninhoud te verhoog. SojaboonBradyrhizobium-simbiose kan ongeveer $300 \mathrm{~kg} \mathrm{~N}^{-1}$ onder gunstige loestande bind.' Omdat sojabone sowat $100 \mathrm{~kg} \mathrm{~N}$ vir elke ton graan benodig, ${ }^{7}$ is opbrengste van 3 ton hat realisties. Faklore wat die hoeveclheid proteïen-N bepaal, sluil tocganklike $\mathrm{N}$ in die grond, genetiese beperkings, aanpasbaarheid van dic simbiotiese pare (kultivar-rhizobiumras) en die afwesigheid van ander opbrengsbeperkende faktore in.

'n Polprocf' is uitgevocr om: (1) dic dic aanpasbaarheid van sekere simbiotiesc pare (kultivar-rhizobiumras-kombinasies) op opbrengs, $\mathrm{N}$ - en proteïeninhoud van dic saad te cvaluecr en (2) die laerkoste konvensioncle en duur isotooptegnicke om atmosfericse $\mathrm{N}$-binding te bepaal, met mekaar te vergelyk. Met die konvensionele tegnick word die atmosferiesgebonde $\mathrm{N}$ as die verskil tussen $\mathrm{N}$-opname deur nodulerende (benut atmosicriese en grond $N$ ) en nie-nodulerende sojabone of 'n ander verwysingsplant (benut net grond $N$ ) bepaal. Dic isotooptegnick behels dic verryking van grond $\mathrm{N}$ met dic spoorder ${ }^{15} \mathrm{~N}$ sodat tussen atmosferiese en grond- $\mathrm{N}$-opname deur dic plante onderskei kan word.

\section{METODES EN PROSEDURES}

Twechonderd kg grond (van die Avalonvorm) uit die Viljoenskroon distrik mel 'n lecmsandtekstuur, is met $500 \mathrm{~g}$ fyn gemaalde miclie-plantmatcriaal vermeng om mikrobelewe te aktivecr. Hierna is dic grond in 'n dun laag oopgesprei en met ' $\mathrm{n} 12 \mathrm{dm}^{3}$ wateroplossing wat $5 \mathrm{~g}$ ammoniumsulfaat $\left(99\right.$ atoom \% $\left.{ }^{15} \mathrm{~N}\right)$ bevat, benat. Die volume oplossing is bereken om die grond tot veldkapasiteit te benat. Die nat grond is deeglik vermeng en in twee plastiekdromme in 'n temperalturbeheerde kamer $\left(30^{\circ} \mathrm{C}\right)$ geplaas. Die grond is na 'n 18-maandestabiliseringsperiode gelugdroog en gesif $(<4 \mathrm{~mm})$.

Daar is vooral met dic kweek van sojaboonplantjies in hierdic grond vasgestel dat Bradyrhizobium japonicum-bakterieë alwesig is. Na die wortelondersock, wat geen nodules opgelewer het nic, is die plantjies vir totale $\mathrm{N}$ en ${ }^{15} \mathrm{~N}$ ontleed om te verseker dat dic konsentrasic ${ }^{15} \mathrm{~N}\left(4,8782\right.$ atoom $\left.\%{ }^{15} \mathrm{~N}\right)$ in dic grond voldoende van die agtergrondwaarde $\left(0,3663\right.$ atoom \% $\left.{ }^{15} \mathrm{~N}\right)$ verskil om sinvolle navorsing te onderneem.

Die potte ( $2 \mathrm{dm}^{3}$ kapasiteit) se bodems is mel $200 \mathrm{~g}$ skoon riviersand bedek en 'n kocldrankstrooitjic, waardeur lug tydens benatting kan ontsnap, is vertikaal teen die kant geheg met die onderpunt in die sand. Van dic eksperimentele grond is 'n verteenwoordigende monster vir ontleding genecm. Daarna is vir elke pol $2500 \mathrm{~g}$ grond afgeweeg en deeglik met $0.82 \mathrm{~g}$ $\mathrm{KH}_{2} \mathrm{PO}_{4}$ vermeng. Dic grond is bo-op dic sand in die potte geplaas en gelyk geskraap. Die waterretensic by $33 \mathrm{kPa}$ is gebruik om die volume gedeioniseerde water te bereken (132 $\mathrm{cm}^{3}$ ) om die grond in die potte volledig te benat. Slegs sowat 65 $\mathrm{cm}^{3}$ hicrvan is plantbeskikbare water en besondere aandag is aan die natmaak van die potte bestee.

Die kultivars Forrest, Prima en A5409 is met geen, WB1 of WB74 Bradyrhizobium japonicum-rasse in alle kombinasies geïnokuleer. Elke behandeling is vier keer herhaal. Sade is vooraf ontkiem en vier per pot geplant deur vier gaatjies in 'n vierkant, sowat $25 \mathrm{~mm}$ van mekaar, $15 \mathrm{~mm}$ dicp te druk en een saad in clke gaatjic te plaas. Volgens behandeling is $1 \mathrm{~cm}^{3}$ van die kultuursuspensies van rhizobiumrasse (0, WBI en WB74) oor clke saad uitgegiet en dic gaatjic met grond gevul. Dic potte is met plastickfilm bedek om uitdroging van dic grond te verminder. Na opkoms is die plastickfilm verwyder en die plante tot ecn per pot uitgedun. Aanvanklik is die waterverlies daagliks een keer aangevul, maar soos die blaredak vergroot het, moes die aanvulling twee tot drie keer per dag gedoen word.

Blare wat afval, is by elke pot in 'n vooraf geweegde, gedroogte en gemerkle papiersakkic versamel. Die bogrondse dele van elke plant is op dic R8-grocistadium ${ }^{8}$ gemonster en in blare, stingels en peule verdeel. Nadat die getal en massa peule per pot bepaal is, is dit in peuldoppe en saad verdecl. Die wortels is uitgespoel vir nodule-evaluasic. Die massa van die alsonderlike plantdele is bepaal. Met ocs was die nodules reeds so verweer dat dit as 'n eenheid saam met die wortels geweeg en ontleed is. A5409 het langer geneem om ryp te word en is 'n week na die ander twee kultivars ge-oes. Plantmonsters is by 65 "C vir 48 uur gedroog en gemaal $(<0,4 \mathrm{~mm})$. Grondmonsters is gelugdroog en fyngemaak ( $<2 \mathrm{~mm}$ ), goed gemeng en pocierfyn gemalal. Sowel plant-as grondmonsters is tot 'n homogene toestand vermeng voordat submonsters vir ontleding 
geneem is. Atoom $\%{ }^{15} \mathrm{~N}$ en $\% \mathrm{~N}$ is volgens erkende melodes ${ }^{9}$ bepaal en \% Nava is bereken. ${ }^{10}$

Die proef is 'n volledige gerandomiseerde ontwerp en analise van variansie is mel PROC GLM van SAS ${ }^{11}$ gedoen. Die prestasiegemiddeldes van dic kultivars is met behulp van Bonferroni paarsgewyse loetse vergelyk." Indien daar lussen kullivars en rasse interaksies was, is die kultivars se gemiddeldes deur middel van ortogonale kontraste met mekaar vergelyk."

\section{RESULTATE EN BESPREKING}

1. Evaluering van die aanpasbaarheid van sekere kultivar-rhizobiumras-kombinasies

\section{Opbrengs en $N$-inhoud van sojaboonsaad}

Ontledingsresultate van die saad in tabel 1 toon dat vir die 0-rhizobiumbehandeling, Prima se saadmassa en massa ${ }^{15} \mathrm{~N}$ beduidend hoër as dié van Forrest is en die massa totale $N$ is beduidend hoër as dié van Forrest en A5409. Met WB1 as inokulant het Forrest 'n betekenisvol hoër saadopbrengs met 'n laer atoom \% " $\mathrm{N}$ as Prima en A5409 geproduseer. Dic \% totale $\mathrm{N}$ in die saad is vir Forrest beduidend laer as vir A54(\%). Daar is 'n betekenisvol groter massa totale $\mathrm{N}$ deur Forrest opgenecm. Die \% Nava is getransformeer na natuurlike logaritmes vanwee heterogene variansies tussen kultivars en rhizobiumrasse. In Forrest is die \% Nava beduidend meer as in Prima en A5409. Hicrdic opnametendense vir dic kombinasic Forrest-WB I geld ook vir Forrest-WB74. Forrest het dus met WBI en WB74 dic grootste saadopbrengs gelewer en die meeste totale sowel as atmosferiese $\mathrm{N}$ benut.

Die Prima-WBI-kombinasie het beduidend minder atmosferiese $\mathrm{N}$ as die ander twee kultivars in die saad ingcbou. Dic saadmassa van Prima-WB I en A5409-WB I verskil nie betckenisvol van mekaar nie. Die atoom \% ${ }^{15} \mathrm{~N}$ en die massa ${ }^{15} \mathrm{~N}$ is dic hoogste in dic saad van PrimaWB1. Omdat Prima-WBI atmosferiese N swakker as Forrest-WB 1 en A5409-WB1 bind, is dic atoom \% ${ }^{15} \mathrm{~N}$ van 5,136 (ras 0 ) net tot 1,765 verdun. Met WBI is Forrest se atoom \% ${ }^{15} \mathrm{~N}$ tot $0,976 \mathrm{cn} \mathrm{A} 5409$ tot 1,514 verdun wat Forrest-WB1 as 'n elfektiewe kombinasic identifiseer,



FIGUUR 1: Massa totale $N$ per pot in plantele op die oesrypstadium vir die kultivar-rhizobiun-kombinasies (Kultivars: $F=$ Forrest, $P=$ Prima, $A=A 5409$, Rhizobitumrasse: $0=$ geen, $I=W B I$ en $74=W B 74$ ).

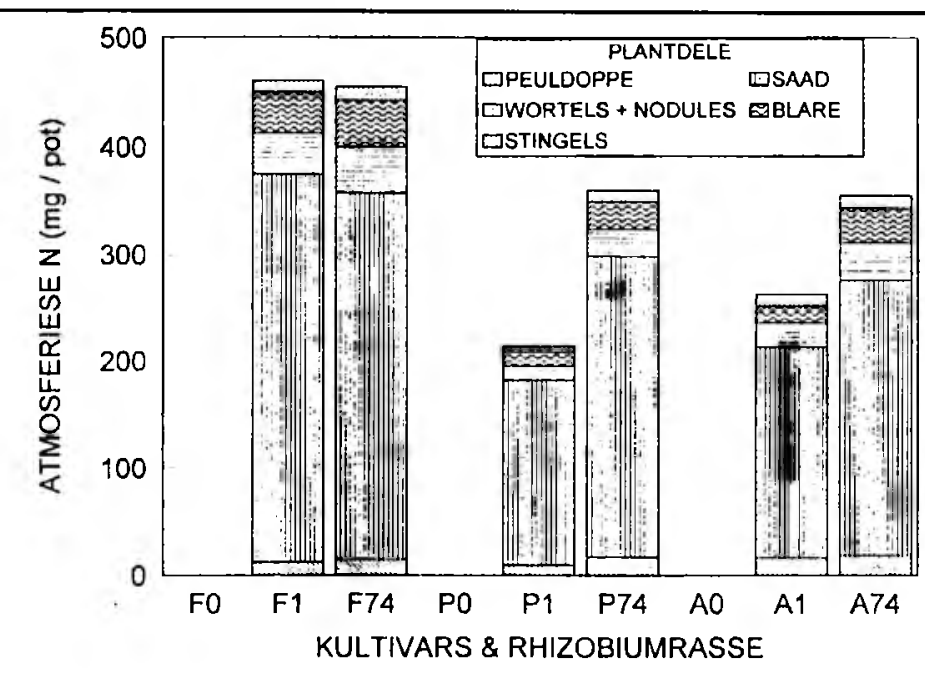

FIGUUR 2: Massa atmosferiese $N$ per pot in plantdele op die oesrypstadium vir die kultivar-rhizobium-kombinasies (Kullivars: F=Forrest, $P=$ Prima, $A=A 5409$, Rhizobium rasse: $O=G e e n, l=W B /$ en $74=W B 74$ ).

TABEL 1 Ontleding van die saad van drie sojaboonkultivars (Forrest, Prima en A5409) wat met geen (0) en twee rhizobiumrasse (WB1 en WB74) geïnokuleer is

\begin{tabular}{|c|c|c|c|c|c|c|c|}
\hline Ras & Kultivars & $\begin{array}{c}\text { Saadmassa } \\
((\mathrm{g})\end{array}$ & $\begin{array}{l}\text { Atoom } \\
\%{ }^{15} \mathrm{~N}\end{array}$ & $\begin{array}{c}\text { Massa }{ }^{15} \mathrm{~N} \\
\left(\mathrm{mg}^{15} \mathrm{~N}\right)\end{array}$ & $\begin{array}{c}\% \text { Totale } N \\
(\% N)\end{array}$ & $\begin{array}{l}\text { Massa } \\
\text { Totale } N \\
(\mathrm{mg} \mathrm{N})\end{array}$ & $\%$ Nava \\
\hline 0 & $\begin{array}{l}\text { Forrest } \\
\text { Prima } \\
\text { A5409 }\end{array}$ & $\begin{array}{l}1,183 b^{\star} \\
1,975 a \\
1,885 a b\end{array}$ & $\begin{array}{l}5,250 \mathrm{a} \\
5,136 \mathrm{a} \\
5,272 \mathrm{a}\end{array}$ & $\begin{array}{l}1,819 b \\
3,619 a \\
2,699 a b\end{array}$ & $\begin{array}{l}2,928 a b \\
3,581 a \\
2,664 b\end{array}$ & $\begin{array}{l}34,619 \mathrm{c} \\
70,544 \mathrm{a} \\
50,857 \mathrm{~b}\end{array}$ & $\begin{array}{l}- \\
-\end{array}$ \\
\hline WB1 & $\begin{array}{l}\text { Forrest } \\
\text { Prima } \\
\text { A5409 }\end{array}$ & $\begin{array}{l}7,933 a \\
4,318 b \\
3,930 b\end{array}$ & $\begin{array}{l}0,976 \mathrm{c} \\
1,765 \mathrm{a} \\
1,514 \mathrm{~b}\end{array}$ & $\begin{array}{l}4,043 a b \\
4,317 a \\
3,669 b\end{array}$ & $\begin{array}{l}5,222 \mathrm{~b} \\
5,664 \mathrm{ab} \\
6,329 \mathrm{a}\end{array}$ & $\begin{array}{l}414,982 a \\
244,254 b \\
253,030 b\end{array}$ & $\begin{array}{l}87,44 a \\
70,60 \mathrm{c} \\
76,39 \mathrm{~b}\end{array}$ \\
\hline WB74 & $\begin{array}{l}\text { Forrest } \\
\text { Prima } \\
\text { A5409 }\end{array}$ & $\begin{array}{l}7,675 \mathrm{a} \\
5,400 \mathrm{~b} \\
4,885 \mathrm{~b}\end{array}$ & $\begin{array}{l}0,883 \mathrm{~b} \\
1,209 a \\
1,198 \mathrm{a}\end{array}$ & $\begin{array}{l}3,396 \mathrm{~b} \\
4,018 \mathrm{a} \\
3,598 \mathrm{ab}\end{array}$ & $\begin{array}{l}5,036 \mathrm{~b} \\
6,257 \mathrm{a} \\
6,218 \mathrm{a}\end{array}$ & $\begin{array}{l}383,611 \mathrm{a} \\
338,925 \mathrm{ab} \\
307,927 \mathrm{~b}\end{array}$ & $\begin{array}{l}89,41 a \\
82,39 b \\
83,06 b\end{array}$ \\
\hline
\end{tabular}

* Simbole in die kolomme wat van mekaar verskil, dui vir elke ras betekenisvolle verskille tussen kultivars aan by $p=0,05$

"\% Nava = Persentasie $\mathrm{N}$ afkomstig van die atmosfeer en data is na statistiese verwerking weer teruggetransformeer 
want hoe beter die Nava, hoe meer word die atoom $\%{ }^{15} \mathrm{~N}$ in die plant verdun. A5409-WBI se waardes lê tussen Prima-WB1 en Forrest-WB 1 . Dic hoe persentasic lotale $N$ in Prima-WB $1 \mathrm{en}$ A5409-WBI is die gevolg van relatiel lac siadmassas. In simbiose met W1374 verskil Prima en A5409 in geen opsig van mekaar nic en is die bepalings vir alle plantdele beduidend verskillend van Forrest-W1374. Hierdie resuitate bevestig die bevindinge ${ }^{12,13}$ dat dalar 'n verwantskap tussen sojaboonkultivar en die stikstolbindende rhizobiumbaktcriec̈ bestain.

In die saad is daar ook 'n verwantskap gevind tussen die atoom $\%{ }^{15} \mathrm{~N}(\mathrm{X})$ en die $\%$ Nava $(\mathrm{Y})$ wat deur $\mathrm{Y}=108,14-21,(09 \mathrm{X}$ met $\mathrm{r}$ $=0,9995$ beskryl word. Vir hierdie stel dala kan die \% Nava met dié formule van die atoom \% ${ }^{15} \mathrm{~N}$ in die saad algelei word. Dit sou moontlik wees om vir elke lokaliteit waar evaluasieproewe in die veld uitgelê word, so 'n verwantskap te bepaal.

\section{Persentasie $N$ afkomstig van die atmosfeer (\% Nava)}

Die proteïengehalte in die saad word van die N-konsentrasie afgelei en hou verband met die biomassaproduksie. Indien die biomassaproduksie reeds optimaal is, moet die N-opname en binding aandag kry om die gewenste proteiengehalte te verseker. Dalarom word veral op dic atmosferiese $N$-binding gefokus. Dic massa lotale en atmosferiese $\mathrm{N}$ in die onderskeic behandelings word in figure I en 2 aangedui.

In figuur I word die totale $\mathrm{N}$ in die plantdele getoon. Dic kontrolebehandelings se $\mathrm{N}$-inhoud in die saad van Prima is belekenisvol meer as dié van fiorrest en A5409. Vir die dric geînokuleerde kultivars blyk dit dat Forrest die meeste $\mathrm{N}$ in die saad, blare en die wortels opgeneem het. Forrest-WBI hevat eliens meer $N$ in die saad as Forrest-WB74. Met Prima-W1374 en A54(1)9-W1374 is meer $N$ in die volledige plant opgeneem en is die $\mathrm{N}$ in die saad en hlare ook hoër as in kombinasie met WB1.

Die atmosferies gebonde $N$ in die plantele word in liguur 2 alangetoon. Die algemene tendens stem ooreen mel figuur 1 watar Forrest-WB 1, Prima-WB74 en A54(9)-WB74 dic beste kombinasic vir hierdie drie kultivars is.

Die \% Nava vir die plantdele is met dic isotooptegnick bepaal en word vir dic onderskeic kultivar-rhizobiunras-kombinasies in tabel 2 weergegec. Tydens die statistiese verwerking was die data vir peule, peuldoppe, saad en tolale bogrondse dele vanweë

TABEL 2 Persentasie $\mathrm{N}$ afkomstig van die atmosfeer (\% Nava) in die plantdele van drie sojaboonkultivars (Forrest, Prima en A5409) wat met 'n kontrole (0) en twee rhizobiumrasse (WB1 en WB74) geïnokuleer is

\begin{tabular}{|c|c|c|c|c|c|c|c|c|}
\hline Rasse & Kultivar & Blare & Stingels & Peule $^{\sharp}$ & Peuldoppe" & Saad" & Bogrondse dele & Wortels \\
\hline WB1 & $\begin{array}{l}\text { Forrest } \\
\text { Prima } \\
\text { A5409 }\end{array}$ & $\begin{array}{l}52,56 \mathrm{a}^{*} \\
27,90 \mathrm{c} \\
35,38 \mathrm{bc}\end{array}$ & $\begin{array}{l}45,69 \mathrm{a} \\
33,69 \mathrm{a} \\
39,22 \mathrm{a}\end{array}$ & $\begin{array}{l}87,27 \mathrm{a} \\
69,22 \mathrm{c} \\
76,14 \mathrm{~b}\end{array}$ & $\begin{array}{l}81,25 \mathrm{a} \\
51,02 \mathrm{c} \\
74,75 \mathrm{~b}\end{array}$ & $\begin{array}{l}87,49 \mathrm{a} \\
70,60 \mathrm{c} \\
76,39 \mathrm{~b}\end{array}$ & $\begin{array}{l}80,39 \mathrm{a} \\
61,46 \mathrm{c} \\
68,02 \mathrm{~b}\end{array}$ & $\begin{array}{l}53,98 \mathrm{a} \\
35,73 \mathrm{c} \\
47,22 \mathrm{~b}\end{array}$ \\
\hline WB74 & $\begin{array}{l}\text { Forrest } \\
\text { Prima } \\
\text { A5409 }\end{array}$ & $\begin{array}{l}52,16 \mathrm{a} \\
38,17 \mathrm{~b} \\
41,00 \mathrm{~b}\end{array}$ & $\begin{array}{l}49,45 \mathrm{a} \\
49,94 \mathrm{a} \\
52,87 \mathrm{a}\end{array}$ & $\begin{array}{l}89,11 a \\
81,48 b \\
82,74 b\end{array}$ & $\begin{array}{l}82,72 \mathrm{a} \\
67,95 \mathrm{~b} \\
79,20 \mathrm{ab}\end{array}$ & $\begin{array}{l}89,41 \mathrm{a} \\
82,39 \mathrm{~b} \\
83,06 \mathrm{~b}\end{array}$ & $\begin{array}{l}80,98 \mathrm{a} \\
73,96 \mathrm{~b} \\
73,38 \mathrm{~b}\end{array}$ & $\begin{array}{l}53,12 \mathrm{ab} \\
48,41 \mathrm{~b} \\
58,01 \mathrm{a}\end{array}$ \\
\hline Raseffekte & & WB74 $>$ WB1 & WB74>WB1 & - & - & WB74 $>$ WB1 & - & - \\
\hline
\end{tabular}

* Simbole in die kolomme wat van mekaar verskil, dui vir elke ras betekenisvolle verskille tussen kultivars aan by $p=0,05$

" Teruggetransformeerde data

TABEL 3 Proteieninhoud (\% en g pot $\left.{ }^{-1}\right)$ van die drie kultivars vir die kontrole en inokulante WB1 en WB74

\begin{tabular}{|l|r|c|c|}
\hline \multirow{2}{*}{ Kultivar } & Kontrole & WB1 & WB74 \\
\hline Forrest & \multicolumn{3}{|c|}{ Proteiene (\%) } \\
\cline { 2 - 4 } Prima & $18,3 \mathrm{ab}$ & $32,6 \mathrm{~b}$ & $31,5 \mathrm{~b}$ \\
A5409 & $22,4 \mathrm{a}$ & $35,4 \mathrm{ab}$ & $37,8 \mathrm{a}$ \\
\hline \multirow{2}{*}{ Forrest } & $16,7 \mathrm{~b}$ & $39,6 \mathrm{a}$ & $38,9 \mathrm{a}$ \\
\hline Prima & \multicolumn{3}{|c|}{ Proteiene (g pot $\left.{ }^{-1}\right)$} \\
\hline A5409 & $0,22 \mathrm{c}$ & $2,59 \mathrm{a}$ & $2,42 \mathrm{a}$ \\
\hline
\end{tabular}

* Simbole in die kolomme wat van mekaar verskil, dui vir elke ras betekenisvolle verskille tussen kultivars aan by $p=0,05$ heterogene variasies na natuurlike logaritmes getransformeer. Dic \% Nava in die bogrondse plantdele van Prima-W131 is beduidend laer as vir Forrest-WBI en A5409-WB1.

Behalwe in die stingels walr die \% Nava vir al die kullivarWB1-kombinasies eenders is, verskil dit in dic ander plantdele soos volg: Forrest-WB $1>$ A5409-WB1 $>$ Prima-WB1. Met dic kultivar-WB74 verskil die \% Nava in die stingels ook nic betekenisvol nie. Die \% Nava in die ander bogrondse plantdele van Forrest-WB74 is betekenisvol groter as vir Prima-WB74 en A5409-WB74. Vir laasgenoemde Iwee kombinasies verskil dic \% Nava in die bogrondse plantdele nie betekenisvol nic, maar in dic wortels met nodules van A5409-WB74 is dit betckenisvol hö̈r as by Prima-WB74.

\section{Proteieninhoud van die saad, massa saad en proteien geproduseer}

Die kultivar-rhizobiumras-kombinasies se invloed op dic proteïenkonsentrasic en massa in die saad en saadopbrengs, word in tabel 3 weergegee.

Sonder rhizobiumbakterieë presteer Prima die beste met die hoogste konsentrasie en massa proteiene. Die proteienwaardes (\% $\mathrm{cn} \mathrm{g} \mathrm{pol}^{-1}$ ) van die kontroles is beduidend laer as dić wat geïnokuleer is. Ongeag dic rhizobiumras waarmee geinokuleer is, is die protcienkonsentrasic in Forrest die laagste en die massa 
proteiene geproduseer die hoogste. Die saadmassa (tabel 1) van geinokuleerde Forrest is ook beduidend meer as die van Prima en A5409. Met 'n populasic van 330000 plante ha' is bereken dat Forrest dus 0,$39 ; 2.62$ en 2,53 ton saad hat met die rhizobiumrasse (), WBI en WB74 respektiewelik produsecr. Resultate soos \% proteien, war konsentrasie van belang is, moet verdunning verreken word ten opsigte van totale massa. Met dic groter saadopbrengs wat Forrest produsecr, kon die grond en rhizobiumbakteriee nie voldoende $N$ voorsien om hoë kwaliteit saadproteien te verseker nie. Om die totale $\mathrm{N}$ in die saad en derhal we die persenlasie proteïene doelgerig te verhoog, kan addisionele kunsmis- $\mathrm{N}$ loegevoeg word, ${ }^{14}$ of meer gunstige kultivar-rhizobiumras-kombinasies gevind word, of die translokasie van $\mathrm{N}$ uit die vegetatiewe plantdele bevorder word.

\section{Die konvensionele versus die isotooptegniek om \% Nava} te bepaal

Met die resultate van kontrolebchandelings wat geen atmosferiese $\mathrm{N}$ bind nie, is vasgestel hoeveel $\mathrm{N}$ sojabone uit die grond opnecm. Gevolglik kan die konvensionele metode sowel as die spoordertegnick nou gebruik word om die persentasie van die stikstof in die plant of plantdele wat uit dic atmosieer gebind is, te bereken. In tabel 4 is die die twee metodes se \% Nava in die hele plant asook in die saad met mekaar vergelyk.

Die resultate van dic twee metodes stem goed ooreen en dic waarnemings lê goed versprei om 'n regressiclyn $Y=-5,6234+$ $1,0336 \mathrm{X}$ waar $\mathrm{X}=\mathrm{konvensionecl-en} \mathrm{Y}=$ isotoop bepaalde \% Nava waardes is. Dic korrelasiekoëflisiënt van $r=0,9466$ bevestig die goeic verwantskap tussen die twee metodes. 'n Enkele alwyking kom voor waar dic konvensionele metode, Prima-WB74 se \% Nava in die saad met 13,5\% oorskat. Hierdic potproef bevestig dat wanneer die kultivar wat bestudeer is in grond sonder rhizobiumbaktericë gekweek is en dit as 'n verwysingsplant vir daardie spesilieke kultivar-rhizobiumraskombinasies dien, albei legnieke gebruik kan word om die \% Nava te bepaal. Indien die kontrole van Prima die enigste verwysingsplante vir al drie kultivars was, dan is die berekende \% Nava vir Forrest en A5409 heelwat laer. Data in tabel 5 bied verklarings vir hierdic teenstrydighede.

Tabel 5 toon dat Prima die vermoě het om beduidend meer $\mathrm{N}$ as die ander twee kultivars deur sowel geinokulecrde as kontroleplante uit die grond te benut. Prima het gemiddeld 146 mg $N$ uit die grond opgeneem en Forrest en A5409 gemiddeld slegs 132 en $133 \mathrm{mg} \mathrm{N}$ respekticwelik. Mel Prima as dic verwysingsplant verklaar dic hoër grond $\mathrm{N}$-opname die laer $\%$

TABEL 4 Berekende gemiddelde \% Nava in die totale plant en saad van die drie kultivars volgens die konvensionele en isotooptegnieke

\begin{tabular}{|c|c|c|c|c|c|c|}
\hline \multirow[t]{2}{*}{ Tegniek } & \multicolumn{3}{|c|}{ WB1 } & \multicolumn{3}{|c|}{ WB74 } \\
\hline & Forrest & Prima & A5409 & Forrest & Prima & A5409 \\
\hline & \multicolumn{6}{|c|}{$\%$ Nava in die PLANT } \\
\hline $\begin{array}{l}\text { Verwysingsplant } \\
\text { Konvensioneel" } \\
{ }^{15} \mathrm{~N} \text {-isotoop } \\
\text { Verskil (plant) }\end{array}$ & $\begin{array}{r}75,4 \\
78,6 \\
77,1 \\
1,5\end{array}$ & $\begin{array}{r}60,0 \\
60,0 \\
58,4 \\
1,6\end{array}$ & $\begin{array}{r}62,7 \\
66,6 \\
65,7 \\
0,9\end{array}$ & $\begin{array}{r}75,2 \\
78,4 \\
77,1 \\
1,3\end{array}$ & $\begin{array}{l}70,9 \\
70,9 \\
71,3 \\
-0,4\end{array}$ & $\begin{array}{r}70,3 \\
73,4 \\
71,6 \\
1,8\end{array}$ \\
\hline & \multicolumn{6}{|c|}{$\%$ Nava in die SAAD } \\
\hline $\begin{array}{l}\text { Verwysingsplant } \\
\text { Konvensioneel" } \\
{ }^{15} \mathrm{~N} \text {-isotoop } \\
\text { Verskil (saad) }\end{array}$ & $\begin{array}{r}83,0 \\
91,7 \\
87,5 \\
4,2\end{array}$ & $\begin{array}{r}71,1 \\
71,1 \\
70,7 \\
0,4\end{array}$ & $\begin{array}{c}72,1 \\
79,9 \\
76,6 \\
3,3\end{array}$ & $\begin{array}{r}81,6 \\
91,0 \\
89,4 \\
1,6\end{array}$ & $\begin{array}{l}79,2 \\
79,2 \\
65,7 \\
13,5\end{array}$ & $\begin{array}{r}77,1 \\
83,5 \\
83,0 \\
0,5\end{array}$ \\
\hline
\end{tabular}

- Verwysingsplant. Prima se kontrole is vir al drie kultivars in die berekeninge gebruik

"Konvensioneel: Elke kultivar se eie kontrole is in die berekeninge gebruik

TABEL 5 Gemiddelde massa ( $\mathrm{mg}$ ) grond $\mathrm{N}$ in die hele plant vir drie kultivars met twee rhizobiumrasse, WB1 en WB74 geïnokuleer

\begin{tabular}{|c|c|c|c|c|}
\hline & \multicolumn{4}{|c|}{ Grond N (mg) } \\
\hline Kultivar & Kontr. & WB1 & WB74 & Gemid. \\
\hline Forrest & $127 b^{\circ}$ & $135 b$ & $135 \mathrm{~b}$ & 132 \\
\hline Prima & $146 a$ & $152 a$ & $141 \mathrm{a}$ & 146 \\
\hline A5409 & $131 \mathrm{~b}$ & $130 \mathrm{~b}$ & $137 a b$ & 133 \\
\hline Gemid. & 135 & 139 & 138 & 137 \\
\hline
\end{tabular}

Simbole in die kolomme wat van mekaar verskil, dui vir elke ras betekenisvolle verskille tussen kultivars aan by $p=0,05$
Nava in die ander twee kullivars. Die verskille in $\mathrm{N}$-opname uit die grond lussen rasse is onbeduidend en daarom die sukses wanneer die nie-nodulerende kontrole van 'n geïnokulecrde kullivar gebruik word om dic almosferiese $\mathrm{N}$-opname vir daardic besondere kultivar te bereken.

Die resultate met Prima as enigste verwysingsplant is teenstrydig met navorsing wat impliseer dat enige nicnodulerende sojaboon wat as verwysingsplante dien, dieselfde hoeveclheid stikstof uit dic grond as dic toetsplante opneem. Daarom word dic bevinding dat dic isotooptegnick meer akkuraat as die konvensionele metode is, ${ }^{15}$ ondersteun.

\section{GEVOI.GTREKKINGS}

* Die beduidende wisselwerking tussen sojaboonkultivars en rhizobiumrasse veroorsaak dat die beste rhizobiumraskombinasie met cen kultivar nie na ander kultivars 
geëkstrapoleer kan word nie.

* Hoe meer $\mathrm{N}$ uit die atmosleer gebind word, hoe groter dic verdunning van die atoom $\%{ }^{1.5} \mathrm{~N}$ in dic sojaboonsaad. Daarom is die ${ }^{15} \mathrm{~N}$-verdunning 'n gocic matstaf om dic kultivar-rhizobiumras-kombinasie met dic beste atmosferiesc $\mathrm{N}$-bindingsvermoë te identifiseer.

* Bradyrhizobium japonictum-rasse WB I en WB74 in simbiose met dric kommersiële sojaboonkultivars, bind baic $\mathrm{N}$ maar nie voldoende om groot opbrengste met hoě proteiengehalte in die saad te verseker nie.

* Kontrolesojaboonplante wat nie nodulecr nic, produseer swak opbrengste met lac proteiengehalte. Daarom verlaag ondoeltreffende inokulasie die gemiddelde opbrengs en kwaliteit van sojaboonsaad.

* 'n Bruikbare verwysingsplant wat bo alle twyfel netsovecl $\mathrm{N}$ uit die grond opneem as dic toctsplante is nie beskikbalar nie en daarom is die berekening van die \% Nava volgens die konvensionele melode nie belroubaar nic.

* Dic isotooptegnick kan wel met veriroue aangewend word om atmosferiese $\mathrm{N}$-binding deur sojabone te bepaal.

\section{DANKBETUIGING}

Dic Proteien-navorsingstrust (PNT) vir dic befondsing van die projek en dic Landbounavorsingsraad (LNR) vir dic mannekrag en fasilitcite. Dr. M. Smit van dic LNR-Instituut vir Graangewasse vir die grond en sojaboonsaad en Jacomina Bloem van die LNR-Navorsingsinstituut vir Plantbeskerming vir dic Bradyrhizobium japonicum-rasse WB1 \& WB74 en evaluering van dic nodules. M. Kidson van dic LNR-Instiluul vir Grond, Klimaat en Water vir die versorging en oes van die potproel $\mathrm{en}$ Marlyn J. van Rensburg van dic Agrimetric Instituut vir hulp met die statistiese verwerkings.

\section{SUMMARY}

On average soyabean (Glycine max (L.) Merrill) yiclds are 1,9 tons hat with $40 \%$ protein in other countries while South Africa averages 1,24 tons ha ${ }^{-1}$ with $34,5 \%$ protcin. Soyabeans require $100 \mathrm{~kg} \mathrm{~N}$ to produce 1 ton ol seed. The soyabean-rhizobium symbioses can however fix $300 \mathrm{~kg} \mathrm{~N} \mathrm{hat}^{-1}$. Experimental yields of up to 8,5 cons ha ${ }^{-1}$ indicate that the genetic potential is hampered in production systems. The answer to a higher soyabcan production is therefore seated in yicld and seed quality improvements rather than in an extended planting area. This study focussed on the effect of cultivar-rhizobial strain combinations on uplake of $\mathrm{N}$ derived from the atmosphere (Ndfa) and compared the conventional and isotope techniques to measure atmospheric $\mathrm{N}$ fixation.

A loamy sand, initially frec of Bradyrhizobitum japonicum bacteria was enriched with ${ }^{15} \mathrm{~N}$ in order to distinguish between $\mathrm{N}$ derived from the soil and that from the atmosphere. The soyabean cultivars Forrest, Prima and A5409 were planted and inoculated with 0, WBI and WB74 and grown in a greenhouse to maturity. The plants were divided into roots plus nodules, stems, leaves, pods and the latter further into husks and seed. The dry mass was determined and the material ground and analysed for total $\mathrm{N}$ and atom $\%{ }^{15} \mathrm{~N}$. The $\mathrm{N}$ derived from the soil and from the atmosphere was calculated using the ${ }^{15} \mathrm{~N}$ isotope technique.

Figures 1 and 2 illustrate the uptake of tolal $N$ and atmospheric $\mathrm{N}$ by different cultivar-rhizobium combinations. The rank order for N uptake is: Forrest-WB I $>$ Forrest-WB74 $>$ PrimaWB74 >A 5409-WB74 >A5409-WBI >Prima-WBI. The Ndla dilutes the ${ }^{15} \mathrm{~N}$ concentration in the plants. The better the fixation the greater the dilution. Results indicate that Forrest pro- duced a much higher yield than Prima or $\mathrm{A.5409}$, utilized more total $\mathrm{N}$ and lixed the most atmospheric $\mathrm{N}$. The $\mathrm{N}$ and protein concentrations were, however, lower than that of Prima. The protein conten of Forrest could be improved by selecting a more favourable Forrest-rhizobial strain combination, improving the translocation of $\mathrm{N}$ from the vegetative parts to the seed and / or by supplementary $N$ fertilization. Both the isotope and conventional techniques are suitable to determine atmospheric $N$ fixation, provided a suitable reference plant is available. The ideal relerence plant is the same cultivar growing in a soil free of rhizobial bacteria. Under farming conditions, rhizobium-frec soils are scarce or non-existent, which renders this kind of experiment unsuitable for field conditions. The " $\mathrm{N}$ isotope technicue proved highly succesful in selecting the cultivar-rhizobial strain combinations with the highest yicld and $N$ lixation capabilities. It is emphasised that the non-inoculated controls produce low yields with low protein contents. The ineffective inoculation of commercially grown soyabeans will reduce the average yicld and protein content of the crop.

\section{IJTERATUURVERWYSINGS}

1. Keyser, H.11. \& Li, F. (1992). Polcntial for increasing biological nitrogen fixation in soybean, Plant Sorl, 141, 119-135.

2. Scotl, W.O. \& Aldrich, S.R. (1983). Modern Soybean Production. $S$ \& A Publication, Champaign, IL. $209 \mathrm{pp}$.

3. Anonymous. (1994). U.S. soybcan production and ulilization rescarch. A report to the Senate Committee on Agriculture. Nutrition and Forestry and House Commitlec on Agriculture. Soybean Rescarch Advisory Institute. Washington, J.C. 69 pp.

4. De Wir. G.A. (1996). Statisticke van die ()liesade Raad. Persoonlike mededeling.

5. Lawn, R.C. \& Byth, D.E. (1989). Saturated soil culture- a lechnology to expand the adaptation of soybean. In Proceedings World Soybean Res. Cont. IV. Ed. A.J. Pascale. pp. 576-581. Asociacion Argentina de la Soja, Buenos Aires, Argentia.

6. Troedson, R.J. (1988). Physiological aspects of the acclimation and growth of soybean (Glucine max (I..) Merrill) in saturated soil culture. l'hl) Thesis, Universily of Queensland.

7. Sinclair, T.R. \& De Wit, C.T. (1975). Photosynthate and nitrogen requirements for secd production by various crops. Science. 189. $565-567$.

8 Fehr, W.R., Caviness, C.E., Burmood, D.T. \& Penninglon, J.S. (1971). Stage development descriptions for soybean. Glycine max (1.) Merrill. Crop Science, 17, 109-120.

9. Botha, A.D.P., Pretorius, D.C.,Johnson, J.C. \& Kidson, M.V. (1992). Utilization of initially-applied labelled ammonium nitrate by three successive crops, S. Afr: J. Plant Soil, 9, 29-33.

10. Talbot1, H.J., Kenworthy, W.J., Legg. J.O. \& Douglass, L.W. (198.5). Soil-nitrogen accumulation in nodulated and non-nodulated soybeans: a verification of the difference method by a $15 \mathrm{~N}$ technique, Field Crops Research, 11, 55-67.

11. SAS Institute Inc. (1989). SAS/STAT User Guide. Version 6, Fourth Edition, Volume 2, Cary, NC: SAS Instilute Inc., $846 \mathrm{pp}$.

12. Senaratne, R., Amornpimol, C. \& Hardarson, G. (1987). Effect of combined nitrogen on nitrogen lixation of soybean (Cilycine max (L.) Merrill.) as affected by cullivar and rhizobial strain, Plamt Soil, $103,45-50$.

13. Danso, S.K.A., Hera. C. \& Douka, C. (1987). Nitrogen fixation in soybean as influenced by cultivar and Rhizobium strain, Plam Soil, $99,163-174$

14. Botha, A.I).P.. Pretorius, ID.C. \& Coctzer. R.L.J. (1996), Invloed van $\mathrm{N}$-bemesting en rhizobiumrasse op opbrengs en $\mathrm{N}$-samestelling van die saad van sojabone (G/ycime max), S. Afi: Tydsk: Plam Gromd. 13, 82-86.

15. Ruschel, A.P., Vose, P.B., Vicloria, R.L. \& Salali, E. (1979). Comparison of isotope techniçues and non-nodulating isolines to study the effect of ammonium fertilization on dinirogen fixation in soybeans, Glycine max (I.) Merrill. Plant Soril, 53, 523-525. 